This is a prepint of an article accepted for publication in Mediation Theory and Practice Copyright @ 2016 Equinox Publishing Ltd Author: Dr Timea Tallodi, University of Essex School of Law

Email: t.tallodi@essex.ac.uk

Reference the final version of the article as

Tallodi, T. (2016). Building Bridges through Learning as Mediation Parties' Lived Experiences:

An Interpretative Phenomenological Analysis. Mediation Theory and Practice. 1 (2), pp. 155-179.

\title{
Building Bridges through Learning as Mediation Parties' Lived Experiences: An Interpretative Phenomenological Analysis
}

\begin{abstract}
While abundant literature has been devoted to describe mediation, there is little research exploring how parties perceive and make sense of the process. This article reports two associated main themes from an innovative qualitative research project conducted to understand the lived experiences of parties to mediation using interpretative phenomenological analysis for the first time in the literature. The findings present (1) learning as the key experience of participants in mediation, a so far neglected angle of the process, and (2) the mediator's compassionate approach involving conveying ample understanding and sensitivity toward parties' needs and concerns as facilitating learning. Meanings and fresh concepts have been generated through sensitive and careful analysis of the cases, providing a rich portrait of the dynamics of learning, and the way learning bridges differences between the sides. Implications for mediators and research are outlined.
\end{abstract}

Key words: mediation; lived experience; phenomenology; interview study; learning; insight; reappraisal; interpretative phenomenological analysis

\section{Introduction}

Mediation theory and handbooks provide abundant information on what should happen in mediation (Beer and Stief 1997; Bennett and Hughes 2005). However, there is a scarcity of foundational research that explores how parties themselves experience the process (Hoskins and Stoltz 2003). Following the calls for qualitative studies involving mediation parties (Bollen and Euwema 2013; Tallodi 2015; Wall and Dunne 2012) this article aims to investigate parties' personal lived experiences of resolving conflict in mediation. It identifies and explores 'learning' as participants' primary experience, and the mediator's stance and tools facilitating learning as a way to resolution. The analysis captures a previously neglected angle of mediation, addressing a major oversight in the literature.

The underlying principle of facilitative mediation, the main mediation model in use in the UK (Lewis 2009; Ridley-Duff and Bennett 2011), is that parties are the experts on their own conflict and are able to develop better solutions than a third party would advise (Riskin 1994). Hence, facilitative mediators primarily apply process interventions assisting parties to arrive to a mutually satisfying agreement that draws on their interests and needs instead of their positions (Alexander 2008).

There are large conceptual and smaller empirical literatures addressing the stages of mediation, and the tools that mediators might best use to facilitate parties gaining understanding of the interests underlying their conflict (e.g. Goldberg and Shaw 2008; Liebmann 2000). Although small in number, some studies provide empirical evidence that in mediation parties can 
This is a prepint of an article accepted for publication in Mediation Theory and Practice Copyright @ 2016 Equinox Publishing Ltd Author: Dr Timea Tallodi, University of Essex School of Law

Email: t.tallodi@essex.ac.uk

engage in self-reflection and gain a clearer understanding of their situation leading to resolution (Barton 2005; Hoskins and Stoltz 2003; Saundry, Bennett and Wibberley 2013). The described processes imply the need for parties' 'learning' as a crucial element of reconciliation in facilitative mediation. However, while another approach called 'insight mediation' (Picard and Jull 2011: 152) centres on learning, since it is defined as a learning process through deepening conversation (Picard and Siltanen 2013), surprisingly, the literature on facilitative mediation neither emphasises learning nor investigates its elements.

\section{Conceptualising learning in mediation}

For a definition one needs to consult the psychology literature, whereby learning is described as 'the act or process of acquiring knowledge or skill' or 'any lasting change in behaviour resulting from experience...' (Oxford Psychology Dictionary 2009: 417). Thus, learning is conceptualised as the sequence of insight and reappraisal (Carey, Carey, Stalker, Mullan, Murray and Spratt 2007). While these processes appear to form important part of mediation termed as 'understanding' (Kovach 1997: 583), 'deeper recognition' (Doherty and Guyler 2008: 35), and as embracing new perspectives resulting in altered interactions (Bennett and Hughes 2005), no study to date has identified and explored insight and reappraisal constituting learning, as the core of facilitative mediation.

It is the literature on psychotherapy that investigates the processes of insight and reappraisal. Although psychotherapeutic approaches and mediation differ in their main goals (Gabel 2003), both work with tense conversations, personal emotions, and seek to exert constructive influence (Kressel, Henderson, Reich and Cohen 2012). These overlaps allow for the concepts of insight and reappraisal described in the psychotherapy literature to be used as reference points, investigating learning in mediation.

Theorists across therapeutic orientations agree that it is the combination of emotional arousal and processing, along with cognitive reflection on their meaning, that brings about the most substantial and transformative insights (Messer and McWilliams 2007; Pascual-Leone and Greenberg 2007). The importance of a safe environment (Greenberg 2002), the potential of facilitative dialogical context to induce insight through self-reflection (Bohart 2007), and the expression of hope and positive view of the self (Hayes, Feldman and Goldfried 2007) are also emphasised. These essential criteria for insight appear to characterise mediation since it is suggested that the mediator aims at inducing reflection and mutual understanding between parties in a safe environment (Rooney 2007), and the new perspectives are the way toward resolution (Menkel-Meadow, Love, Schneider and Sternlight 2005). Cognitive reflection is accompanied by emotional processing (Barsky 1983).

Although not as a central aspect, mediation's goal to induce reappraisal and its links to Lazarus's (1991) cognitive appraisal theory has been paid some attention (Jones 2005; Tallodi 2015). Mediation was found to elicit parties' reappraisal of the situation, being a 'catalyst' that sets the individuals in motion (Tallodi 2015: 30). It was suggested that for reappraisal to occur, the mediator works to ensure safe space for open conversation and uses effective questioning (Jones and Bodtker 2001; Tallodi 2015). While insight and reappraisal seem to be essential for reconciliation, we lack information about how mediation parties perceive and make sense of these processes and the mediator's intervention.

According to mediation theory, the perceptions of the mediator's empathy, rapport building, warmth, and respect, prime parties' openness to changes in mediation (Herrman, 
This is a prepint of an article accepted for publication in Mediation Theory and Practice Copyright @ 2016 Equinox Publishing Ltd Author: Dr Timea Tallodi, University of Essex School of Law

Email: t.tallodi@essex.ac.uk

Hollett and Gale 2009). In the process the mediator is 'omnipartial', reflecting deep attentiveness and consideration for both parties (Bowling and Hoffman 2000: 12). A questionnaire study with mediation parties documented that the mediator's personal qualities and stance significantly influence mediation's success (Thoennes and Pearson 1985). Mediators in a survey study highlighted that achieving parties' trust had been due to convincing both parties that they, as mediators, genuinely cared about the parties' concerns (Goldberg and Shaw 2008). Although these results suggest qualities that might play an important role in inducing parties' learning, the detailed exploration of mediation parties' personal experiences is vital for the in-depth understanding of the process.

This article, being the output of the first study in the literature using in-depth interviews with mediation parties and interpretative phenomenological analysis, investigates the processes taking place in facilitative mediation as lived by the parties themselves. The analysis (1) describes learning as participants' key experience of mediation, identifying insight and reappraisal as its underlying dynamics; (2) outlines participants' perception that it is through learning that the mediator 'builds bridges' between the parties, facilitating settlement and/or reconciliation; and (3) explores participants' experience of the mediator demonstrating compassion, understanding and sensitivity toward parties' concerns as vital to maximise successful learning. Such an exploration is critical for the understanding of mediation's underlying dynamics and maximizing its benefits.

The findings are an output of a larger qualitative study on the lived experiences of parties to mediation conducted in the UK. The study focused on relational changes in mediation. Therefore, workplace mediation was chosen as the focus, due to the likelihood of parties' involvement in an on-going and intense relationship after mediation (Mareschal 2002). As this article concentrates particularly on the learning process in mediation, the findings have implications for various areas of mediation. It seeks to add depth to existing knowledge on mediation and introduce interpretative phenomenological enquiry to the field. The findings have strong potential to shape the work of mediators and mediation training programs.

\section{Methodology}

In order to study in-depth the lived experiences of parties to mediation interpretative phenomenological analysis (IPA) was chosen. IPA is a major distinctive approach to phenomenological research in psychology (Smith 2011a). Phenomenological psychological research seeks to gain accurate understanding of situations lived by individuals, capturing as closely as possible the way the phenomenon is experienced by the individual (Willig 2008). On this basis, IPA is concerned with the detailed exploration of personal lived experience, the participant's perceptions of the experience and sense-making activities (Smith and Osborn 2008). IPA requires the intensive and rigorous analysis of each individual's account with the possibility to move the analysis to a more theoretical level, looking for generic overarching patterns across cases (Smith and Eatough 2006).

IPA, due to its idiographic nature, uses small samples and focuses on the individual voice (Smith, Flowers and Larkin 2009). Numerous studies are based on interviews with three to six participants (Howitt 2010). Increasingly, studies of a single case (e.g. Rhodes and Smith 2010), or the detailed exploration of a major theme in a wider study are published (e.g. McIntyre and Reynolds 2011). 
This is a prepint of an article accepted for publication in Mediation Theory and Practice Copyright ( 2016 Equinox Publishing Ltd Author: Dr Timea Tallodi, University of Essex School of Law

Email: t.tallodi@essex.ac.uk

IPA's small sample sizes ensure the potential for in-depth analysis, and the focus is placed on transferability of findings from group to group, rather than generalisation (Hefferon and Gil-Rodriguez 2011). Experiences identified through the analysis are existent, resulting in the possibility for their reoccurrence (Willig 2008). Therefore, the findings of this research will provide nuanced insight into participants' inner experiences of mediation, which can be expected to emerge as parties' potential reactions in other mediations.

\section{Participants}

Participants were parties to mediations that ended with a settlement. The study received ethical approval and participants were recruited through staff of organisational (in-house) mediation services in the UK. Five participants from public organisations volunteered to take part in this study. Four participants were employees of the same organisation and their cases were mediated by the same mediator. Two participants participated in two mediations, three participants had one mediation. The interviews were conducted 5 weeks to 4 months after mediation, in order to provide sufficient time for insights achieved in mediation to manifest (Hoskins and Stoltz 2003). Table 1 showcases the brief profile of each participant. The table uses pseudonyms, however, when a participant did not reveal names, codes are being used.

\begin{tabular}{|c|c|c|c|c|c|c|}
\hline Name & $\begin{array}{l}\text { Level of } \\
\text { employment } \\
\text { (all public) }\end{array}$ & $\begin{array}{l}\text { Other } \\
\text { party(ies) }\end{array}$ & $\begin{array}{l}\text { Mediation } \\
\text { timing }\end{array}$ & $\begin{array}{l}\text { Interview } \\
\text { timing } \\
\text { (after } \\
\text { mediation } \\
\text { ) }\end{array}$ & Mediator & $\begin{array}{l}\text { Overall } \\
\text { experience } \\
\text { with } \\
\text { mediation }\end{array}$ \\
\hline Linda & $\begin{array}{l}\text { subordinate, } \\
\text { union } \\
\text { representative }\end{array}$ & $\begin{array}{l}\text { Darren, } \\
\text { supervisor }\end{array}$ & $\begin{array}{lr}\text { after } & 6 \\
\text { weeks } & \text { of } \\
\text { conflict } & \\
\end{array}$ & 3 months & Iris & positive \\
\hline Bob & supervisor & $\begin{array}{l}\text { Helen, } \\
\text { subordinate }\end{array}$ & $\begin{array}{l}\text { after } \quad 6-7 \\
\text { years of } \\
\text { conflict }\end{array}$ & 5 weeks & Iris & positive \\
\hline Jeff & supervisor & $\begin{array}{l}\text { Martin, } \\
\text { subordinate }\end{array}$ & $\begin{array}{lr}\text { after } & 6 \\
\text { weeks of } \\
\text { conflict }\end{array}$ & 5 weeks & Iris & positive \\
\hline Grace & subordinate & $\begin{array}{l}\text { LD ('lead } \\
\text { director') } \\
\text { SM ('senior } \\
\text { manager'), } \\
\text { both members } \\
\text { of senior } \\
\text { management }\end{array}$ & $\begin{array}{lr}\text { after } & 6 \\
\text { years } & \text { of } \\
\text { conflict } & \end{array}$ & 4 months & Iris & $\begin{array}{l}\text { negative } \\
\text { positive }\end{array}$ \\
\hline Emily & subordinate & $\begin{array}{l}\text { Kelly, manager } \\
\text { Kate, co- } \\
\text { worker }\end{array}$ & $\begin{array}{l}\text { after } 16 \\
\text { months of } \\
\text { conflict } \\
\text { and } \\
\text { post } \\
\text { grievance } \\
\end{array}$ & 5 months & Kevin & $\begin{array}{l}\text { negative } \\
\text { negative }\end{array}$ \\
\hline
\end{tabular}


This is a prepint of an article accepted for publication in Mediation Theory and Practice Copyright @ 2016 Equinox Publishing Ltd Author: Dr Timea Tallodi, University of Essex School of Law

Email: t.tallodi@essex.ac.uk

\section{Table 1: Participants' profile}

\section{Interviews}

The data was collected through semi-structured interviews. Prior to the interviews participants were provided with an information sheet along with the opportunity to discuss any queries with the researcher. All participants agreed to take part on the basis of informed consent.

In line with IPA's commitment, the interviews aimed at entering the psychological and social world of the interviewee as deeply as possible (Smith and Osborn 2008). The interviews were semi-structured in that the interviewer highlighted broad topics of interest using a schedule but encouraged participants to introduce issues relevant to their experiences of mediation, working with them flexibly to identify and interpret meanings that they used to make sense of a topic (Reid, Flowers and Larkin 2005). The interviewer stimulated self-refection, requested description and examples, placing emphasis on establishing rapport and safety, the crux of phenomenological interviewing (Wimpenny and Gass 2000). The questions included: How would you describe mediation as an experience for you?, What did the process bring for you?, What is the most remembered conversation you had in mediation?, How was the mediator acting then?, What was this like for you?. The interviews lasted from 51 to 72 minutes.

\section{Data analysis}

Verbatim transcripts were prepared and subjected to IPA. The guidelines offered by Smith, Flowers and Larkin (2009) were used to inform the analysis. Each transcript was analysed individually, preparing a single case analysis of each account.

The analysis began with a close interpretative reading of the first case to enable familiarity. Next, the researcher coded smaller units of the text, systematically interpreting each meaning unit. The coded text was revisited and descriptive, linguistic and conceptual exploratory comments were assigned to the transcript. Subsequently, codes and comments were translated into emergent themes at higher level of abstraction. The themes were interrogated in order to find connections between them, creating main themes. The researcher was focusing on staying open to the particular experience of the participant, leaving preconceptions behind, that is, 'seeing afresh' the data, a main feature of phenomenological attitude (Finlay 2014: 122).

Following the detailed analytic treatment of each individual case, in order to move the analysis to a more theoretical level, the transcripts and analyses were revisited looking for common patterns across cases (Smith and Eatough 2006). Based on IPA's commitment to place the individual and the particular into the centre of attention, the researcher looked for ways in which participants' experiences share higher order qualities and concepts, while displaying the unique idiosyncratic manifestation of these concepts and qualities for the participant (Smith, Flowers and Larkin 2009). Each stage of the analysis was discussed with two supervisors, acting as co-researchers during the analysis, who audited the themes to ensure that they were grounded and well presented in the transcripts (Smith and Osborn 2008).

\section{Results}

As the result of the data analysis several recurring themes emerged. Two main themes that relate to learning as participants' predominant experience in mediation are presented here: (1) 'Building bridges: The mediator who demonstrably understands and cares', and (2) 'Mediation as learning'. It is worth noting that these experiences were difficult to consider as being isolated 
This is a prepint of an article accepted for publication in Mediation Theory and Practice Copyright @ 2016 Equinox Publishing Ltd Author: Dr Timea Tallodi, University of Essex School of Law

Email: t.tallodi@essex.ac.uk

from participants' experiences of relationship change, which, therefore, are entwined in the analysis. In order to preserve the richness of the accounts, the extracts are presented including pauses, conversation fillers, repetitions and false starts.

\section{Theme: Building bridges: The mediator who demonstrably understands and cares}

This theme gathers participants' perceptions of the mediator's approach and tools that supported learning in mediation as the crux of coming to a resolution. The accounts attributed primary significance to the mediator's approach of demonstrating understanding and caring behaviour towards the parties. The mediator was depicted as a 'gentle person' (G: 751) who had genuine interest in parties' concerns and needs, and in finding ways to address these: 'she (the mediator) knew that that's what probably was the issue and I needed to feel that' (G: 360-361). Participants found that the mediator was 'really good' (L: 649), manifesting in excellent listening and communication skills: (the mediator) 'could you know communicate herself and she was a very good listener' (J: 298-299).

Participants described the mediator as a figure who was very actively working on bringing the parties' viewpoints closer to each other's by inducing learning. As the core of the mediator's work, provision of protection and safe space, actively drawing out constructive content from the adversarial dialogue, and ample encouragement through compassionate attitude were highlighted. The mediator's actions were guided by authentic determination to understand both parties' needs in-depth and genuine concern to drive parties toward a resolution that accommodates these.

Subtheme: Feeling protected: Safe space. Participants underline the presence of a safe environment provided by the mediator, a precondition of addressing underlying issues (Crawford, Dabney, Filner and Maida 2003). Jeff encapsulates the essence of safe space as 'feeling at home'. His metaphor indicates that the mediator created an atmosphere whereby Jeff could feel comfortable and relaxed, despite being uncertain about what to expect form mediation.

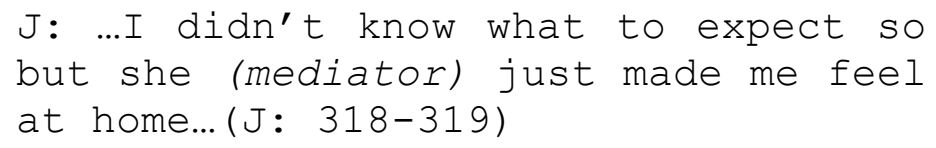

Safe environment for all participants allowed for a 'novel encounter' with the other party, a characteristic of mediation highlighted by Hoskins and Stoltz (2003: 344). This, for Grace, manifested in feeling protected to list her issues and inquire about the reasons for perceived maltreatment. Saundry, Bennett and Wibberley (2013) had found that safe space to have one's voice heard and express previously suppressed content is a commonly reported advantage of mediation. The idea of this conversation was frightening for Grace and mediation helped her, in a vulnerable power position, to provide and achieve insight without feeling as if she was risking her job. This implies an emotionally and psychologically safe environment described by Love (2000b).

G: ...I wanted to get it off my chest

and I wanted to be honest because 
This is a prepint of an article accepted for publication in Mediation Theory and Practice Copyright @ 2016 Equinox Publishing Ltd Author: Dr Timea Tallodi, University of Essex School of Law

Email: t.tallodi@essex.ac.uk

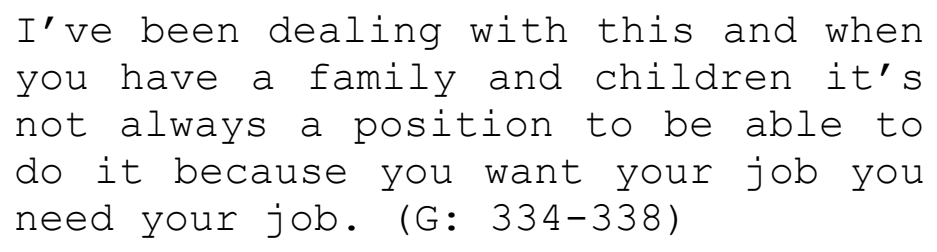

Bob captures the essence of mediation as a facilitated conversation where the mediator ensures safety and 'guides' (B: 1264) the exchange towards insight and reappraisal. Bob felt the ability to speak freely, being supported in re-assessing his issues with Helen and come to a solution that is 'beneficial to everybody' (B: 1268). These factors are a key to change procedures in a dialogical context (Knight, Richert and Brownfield 2012). Therefore, mediation as a unique encounter involved the opportunity to gain constructive insights facilitated by the safety that the mediator provided.

Subtheme: Drawing out constructive content. Participants highlight the mediator's active stance in bringing their standpoints closer. They report that the mediator skilfully balanced among effective questioning, active listening, and rewording, to move the conversation to a constructive path. Constructive communication is an essential element of successful mediation (Kovach and Love 1998) and participants underlined that it was this that paved the way for reappraisal, providing them with a different perspective on their issues.

In Grace's words the mediator offered parties a stage to talk to each other directly, 'reiterating' (G: 359) the expressed content. In the account reiteration implies paraphrases and reframes as termed by Bennett and Hughes (2005).

The mediator called attention to the parties' felt need to work together as a shared interest, a commonly suggested benefit of mediation (e.g. Love 2000a). Also, the mediator highlighted and LD's appreciation of Grace, responding to Grace's expressed need for being valued. The tools aimed at building bridges between the parties by eliciting insight and reappraisal.

G:...she (the mediator) was just
trying to settle things really that
[pause] [breathes] we needed to work
together that we'd established that
um the [pause] [LD] did value me as
a member of staff ... (G:365-368)

Grace reports that in her mediation with SM insight into each other's vulnerabilities and needs broke down the barrier between the parties. For Grace, the mediator highlighted the positive content expressed by SM, reiterating SM's words, and making her confirm that she valued Grace. Subsequently, the mediator checked what feelings these insights induced in Grace, prompting the expression of positive content by both parties. The mediator successfully fulfilled Grace's expressed needs, a frequently mentioned objective of mediation (e.g. Alexander 2008).

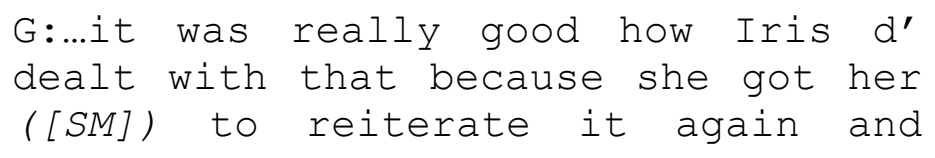


This is a prepint of an article accepted for publication in Mediation Theory and Practice Copyright @ 2016 Equinox Publishing Ltd Author: Dr Timea Tallodi, University of Essex School of Law

Email: t.tallodi@essex.ac.uk

then I said 'I really needed to hear

those things because I've got really

down with not hearing them...' (G:

$616-618$ )

Jeff portrays that the mediator underlined the parties' acknowledgement of a third person's negative influence in their dispute, reducing the confrontation and helping the parties to move on, while saving face. The mediator successfully strengthened mutual commitment to make peace. This is confirmed by a 'secret gem' (Smith 2011b: 12), a single utterance with analytic leverage and significance disproportionate to its size that hints at a phenomenon under the surface. Jeff's verbal slip 'we I also want to move on' uncovers the parties' alliance, reflecting their psychological fusion in the quest to end the dispute.

J: ... Iris came in and she says um um
'It's good that both of you have
realised that you know somebody has
been playing [pause] playing up' so
um it's sort of um it's better to
you know to end the matter here so
that's what she said and I said 'Yes
yeah I want to move on' so he also
said 'Yes ok we I also want to move
on' so she offered us to have a
handshake. (J: $410-415$ )

Subtheme: Encouragement through being compassionate. As a vital factor facilitating learning, participants embraced moments when the mediator actively encouraged them prior to and during the process. In Jeff's words: 'we needed somebody to encourage us to you know sit down and talk' (J: 472).

Two passages of Linda will illustrate the most significant features of the mediator's encouragement. Encouragement is encapsulated in Linda's perception of the mediator as understanding and caring toward parties. She makes sense of these features as being central to building bridges between the parties by inducing constructive insights and reappraisal. Although these characteristics also crop up in other accounts, Linda's examples are particularly vivid and clear.

Linda's need for encouragement started before the joint session when she felt anxious and fearful. Linda doubted if the stress of mediation was worth facing, and her anxiety necessitated encouragement from the mediator to tackle. She perceives empathy, warmth and safety, prerequisites of change in mediation (Herrman, Hollett and Gale 2009), as underlying the mediator's active encouragement

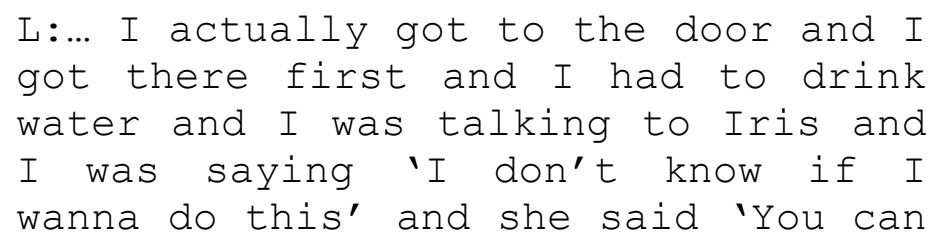


This is a prepint of an article accepted for publication in Mediation Theory and Practice Copyright @ 2016 Equinox Publishing Ltd Author: Dr Timea Tallodi, University of Essex School of Law

Email: t.tallodi@essex.ac.uk

walk out any point Linda'... (L: 593-

596)

Linda explains that starting the joint session both parties refused to speak, requiring the mediator's assistance. The mediator's role to encourage parties to tell their stories emerges in the literature (Bennett and Hughes 2005). Linda makes sense of the background dynamics of the successful encouragement as the mediator's understanding the parties 'both as people... and personalities' (L: 653). For her, the mediator's curiosity and sensitivity towards parties' personalities and wishes, and the understanding she had gained during the intake session, facilitated efficient encouragement for insight and reappraisal. This reflects Linda's perception of the mediator as omnipartial, as described by Bowling and Hoffman (2000).

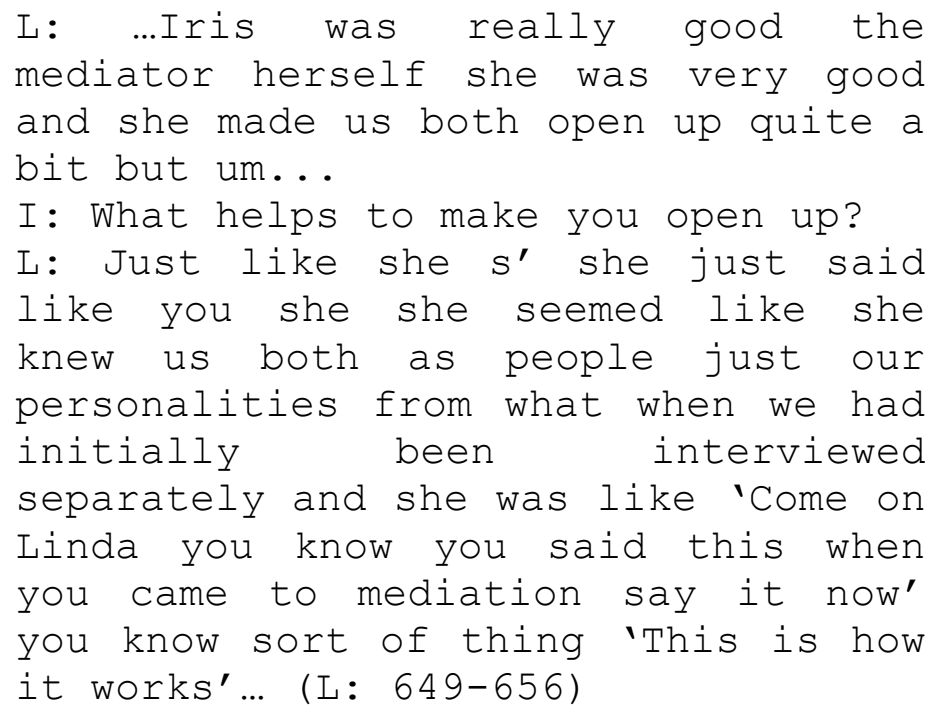

The accounts reveal that it was via compassionate attitude, understanding and active encouragement that the mediator managed to elicit the reinstatement of communication and a successful learning process.

It is important to note, that contrary to all others, Emily, the only participant who reports a strong negative overall experience with mediation, does not elaborate on the mediator's intervention. Instead she speaks about her sense of vulnerability and lack of protection throughout the process. Emily articulates that in mediation she was not successfully assisted to stand up for herself, feel empowered and achieve recognition of her aims, essential factors in facilitative mediation (Rock 2004).

Without feeling supported in mediation, and missing empowerment and recognition, Emily felt she needed to give in, which 'destroyed' a part of her. She reflects on her conversation in mediation with Kate:

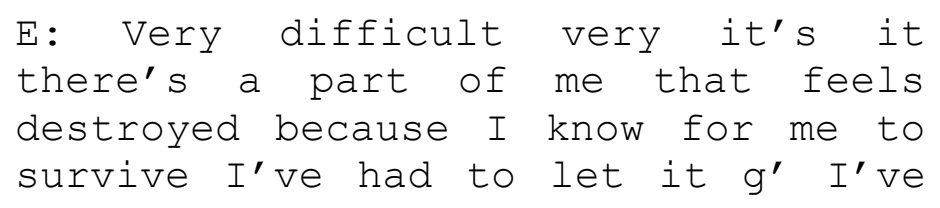


This is a prepint of an article accepted for publication in Mediation Theory and Practice Copyright @ 2016 Equinox Publishing Ltd Author: Dr Timea Tallodi, University of Essex School of Law

Email: t.tallodi@essex.ac.uk

had to accept her version of events.

$(\mathrm{E}: 529-531)$

The negative outcome, the mediator's figure as 'unremembered' and providing no support, confirm the importance of the mediator who is perceived as being sensitive to parties' concerns and actively promoting reconciliation.

\section{Theme: Mediation as learning}

Participants experienced mediation as a learning process, incorporating insight into and the reappraisal of the situation. These processes encompassed participants' way to reconciliation and/or settlement, and became gradually articulated as the interview unfolded. Although the two processes emerge as closely linked, some passages make their separate presentation possible.

Subtheme: Insight as part of learning. Participants recall gaining insight in three dimensions: in relation to the other party, the self, and the situation. They outline attaining new perspectives both during and after mediation, conveying positive or negative content. Even in case of negative understandings, insight itself positively affected the participant by inducing altered thinking about the situation.

Insight occurred in the form of a spiral, whereby one party's disclosure triggered the same of the other, gradually entering deeper layers in the conversation. Heightened emotions accompanied disclosure, facilitating in-depth processing as argued by Whelton (2004). Grace's account vividly captures the spiral, which she perceived as parties acquiring clearer perceptions of each other.

Feeling safe in mediation, Grace commenced the spiral process of deepening insight. She expressed her desire to be valued for the quality of her work and her disappointment at not having her needs fulfilled. She articulated the imbalance between her invested efforts and received rewards, providing insight into her perceptions of effort-reward imbalance (Siegrist 1996), a commonly listed stressor in the background of workplace conflict (Tallodi 2015).

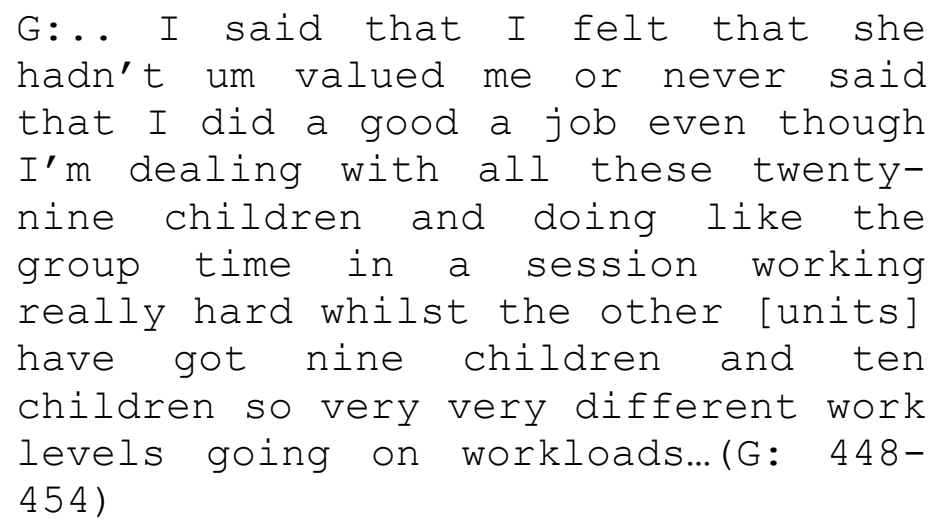

Grace witnessed that her disclosure prompted SM to reveal her perception of Grace as self-confident and professional. SM unveiled that Grace's appearance had led her to the assumption that Grace did not need support. Heightened emotions are portrayed as accompanying the conversation from the start. 
This is a prepint of an article accepted for publication in Mediation Theory and Practice Copyright ( 2016 Equinox Publishing Ltd Author: Dr Timea Tallodi, University of Essex School of Law

Email: t.tallodi@essex.ac.uk

G:... she burst into tears and she
these very things she said 'You
always look and seem so confident
and you do your job so well with
such enthusiasm ...' (G: 456-458)
...
G:... 'and all those things altogether
made me think you don't need any
kind of pat on the back'.. (G:473-
475)

Next, Grace emphasised the misperception. She permitted further insight into her feelings, asking questions about the reasons for being excluded and underappreciated. These elicited SM's final disclosure, further intensifying emotional arousal. Grace's account showcases the simultaneous presence of emotional and cognitive processing occurring in mediation, the primary condition of transformative insights (Messer and Williams 2007). Grace shares that SM revealed that her unfortunate reactions were due to her developmental disorder, a shocking piece of information previously unknown to Grace. The confession made SM highly vulnerable, affirming the safe environment of mediation.

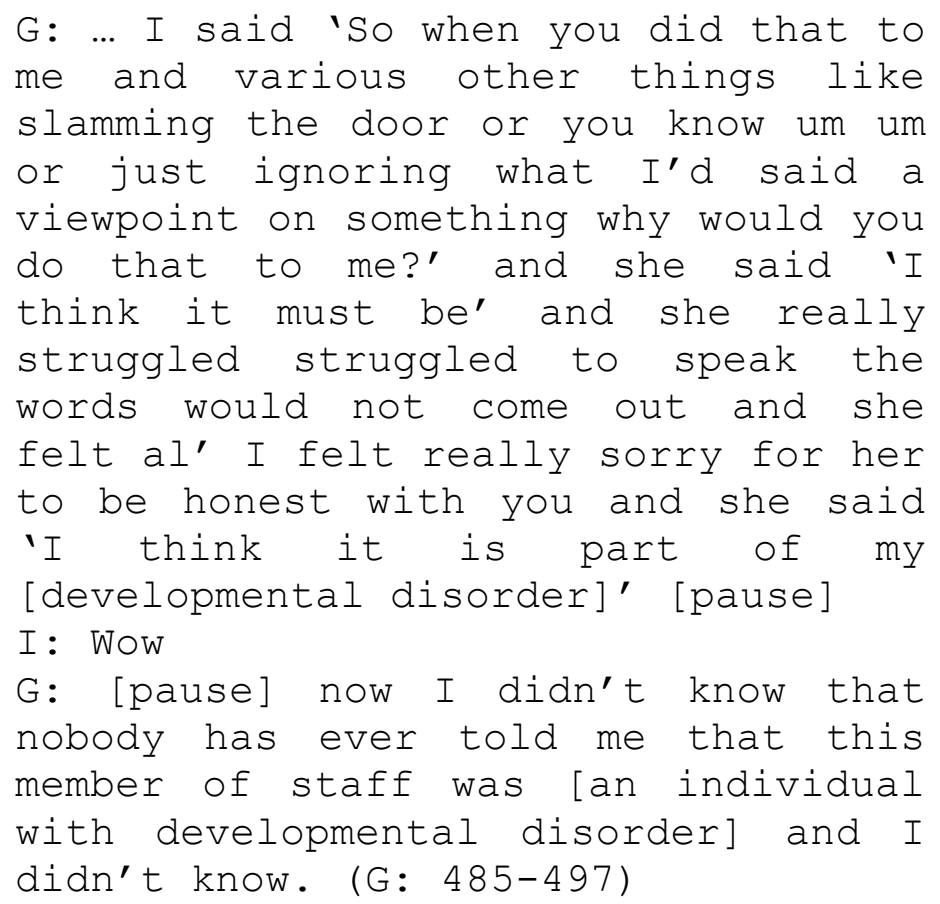

Some participants also reflect upon insights gained about themselves, indicating mediation's potential to increase self-awareness. For Jeff, open communication facilitated recognition of his own contribution to the outbreak of conflict. He realised the possible accusatory quality of his question when enquiring about the length of his subordinate's break time, and the importance of framing questions adequately. Mediation disrupted avoidance of difficult issues, a factor supporting insight (Hayes, Feldman and Goldfried 2007). 
This is a prepint of an article accepted for publication in Mediation Theory and Practice Copyright @ 2016 Equinox Publishing Ltd Author: Dr Timea Tallodi, University of Essex School of Law

Email: t.tallodi@essex.ac.uk

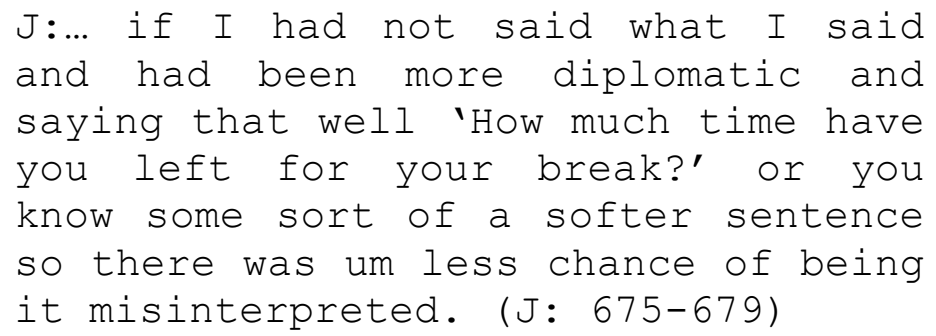

Additionally, all participants attained a clearer perception of the situation more broadly. For Linda, this involved understanding factors beyond the dyadic relationship, a crucial factor in the success of mediation: '(mediation) works because loads of stuff came out um that you wouldn't expect from people' (L: 136).

In Emily's case, the understandings gathered about her situation were entirely negative. She explains that her mediations were unsuitable to terminate the antagonism between the parties. At first sight, it appears that mediation brought 'nothing' for Emily, as she reports. However, elaborating on the insights mediation elicited, Emily articulates her painful comprehension that unfairness and broken relationships are persistent. She makes meaning of mediation as a 'big kick', foreshadowing reappraisal and change. This underlines the positive impact of negative insights, and confirms that mediation helps manage parties' expectations of what may be achieved in a situation (Barton 2005).

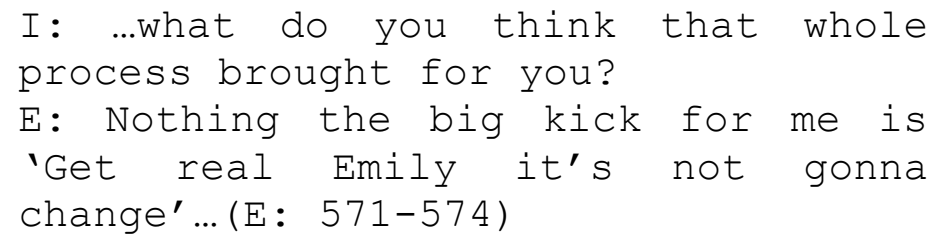

Subtheme: Reappraisal as the way to change. The achieved insights stimulated alterations in participants' thoughts and feelings about their situation, prompting search for different coping strategies. Mediated agreements incorporated changes in behaviours and working practices, and reappraisal informed participants' behaviour beyond the agreement. This refines the results of Seargeant's (2005) pilot study that a number of mediation agreements involved behavioural modifications.

If an amicable relationship was not established or reinstated, reappraisal helped participants develop strategies to handle their situation, clarifying and supporting the results of research reports (e.g. Saundry and Wibberley 2012). Participants' frequent pauses and hesitation in this section highlight the complexity of these issues for them.

Bob in the communication spiral experienced a stream of mutual denial and Helen's sudden shift into becoming accepting of Bob's arguments. He found that for this move to happen the conversation had to arrive to an emotional 'peak' (B: 532). Bob powerfully demonstrates the emotional process that, in his perception, led to Helen's reappraisal of the situation. He uses a metaphor portraying the conversation for Helen as walking along a plank in the air, and the difficulty of reappraisal, as jumping at the end of the plank. Bob explains his perception that Helen needed his offer to re-instate the relationship in order to take the risk and 'jump'. 
This is a prepint of an article accepted for publication in Mediation Theory and Practice Copyright @ 2016 Equinox Publishing Ltd Author: Dr Timea Tallodi, University of Essex School of Law

Email: t.tallodi@essex.ac.uk

B:...she'd got herself into a she'd
like gone along a plank and she'd
got to the end of it you know when
she burst into tears and she was
'Shall I jump or shan't I jump?' um
and when I said to her 'oh yeah we
can have a cuddle' she were like 'Oh
doh I've to jump now'. (B: 1120-
l125)

Bob reports that mutual reappraisal resulted in a settlement: 'it (mediation) sorted it for me personally' (B: 662). However, he believes that Helen's dispute with other team members will not change due to Helen being adamant in her behaviour: 'at the end of the day it's whatever is in Helen's head' (B: 1118). Understanding Helen's tendency, and re-evaluating his situation and invested efforts, Bob decided to retire in three years, a major change in life aims brought about by reappraisal. Although the reconsideration led to mixed outcomes, Bob feels that the decision of future retirement offered him calmness and relief. He portrays his feelings at the end of mediation as follows:

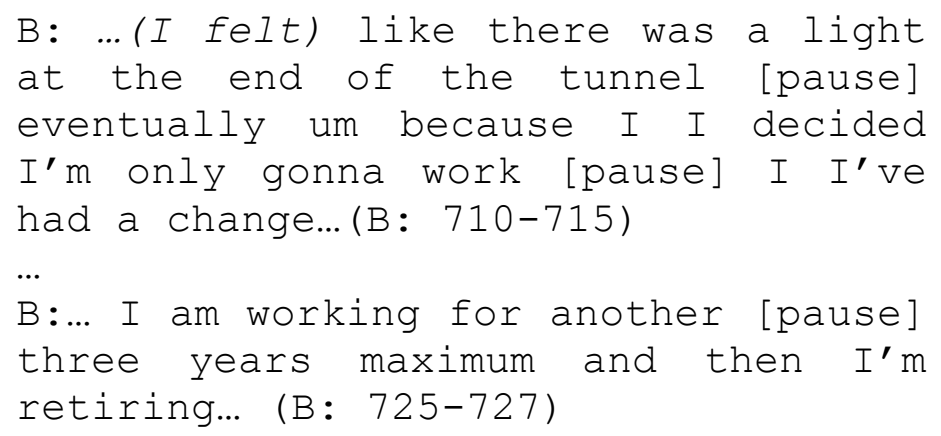

Reappraisal resulted in heightened consideration of the self also for Emily. Insights into the on-going negativity in the work environment led to reappraisal that positively affected Emily. She decided to concentrate on her own well-being and handle her working relationships differently, a change in coping strategies (Folkman, Lazarus, Dunkel-Schetter, DeLongis and Gruen 1986).

E:... the focus became about me actually about trying to repair me ... (E: 791$)$

Learning in mediation brought about an agreement and reconciliation for Jeff, who portrays that parties were able to re-start 'working in a normal fashion' (J: 618). Jeff articulates that mediation has 'given ( $\mathrm{him}$ ) a lesson' ( $\mathrm{J}$ : 654), inducing alteration in his patterns of dealing with disagreements in general. The changes incorporated accepting responsibility and selfcontrolling, which are distinct coping strategies following reappraisal (Folkman et al. 1986). Jeff voices that this transformation requires conscious effort to implement. 
This is a prepint of an article accepted for publication in Mediation Theory and Practice Copyright @ 2016 Equinox Publishing Ltd Author: Dr Timea Tallodi, University of Essex School of Law

Email: t.tallodi@essex.ac.uk

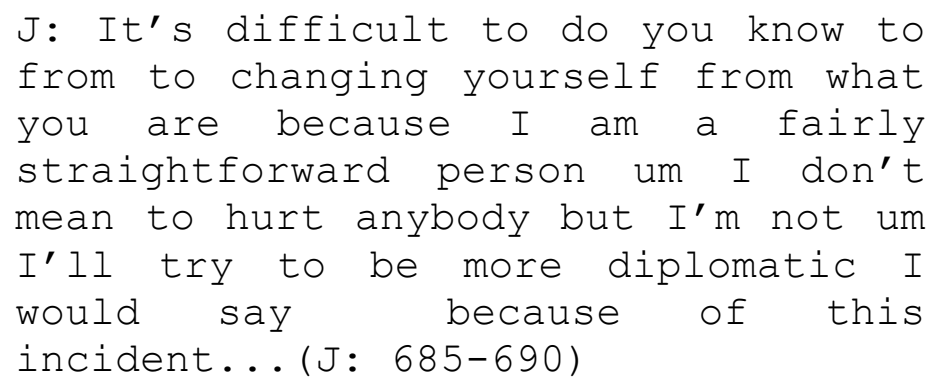

Reappraisal for Linda manifested in an emotional shift in the parties' relationship, and substantial behavioural and emotional alterations beyond the agreement. Learning about Darren's conditions and perspective erased Linda's negative feelings, triggering liking and sympathy for him. Linda's laughter reveals embarrassment when she is disclosing how she was feeling at the end of mediation.

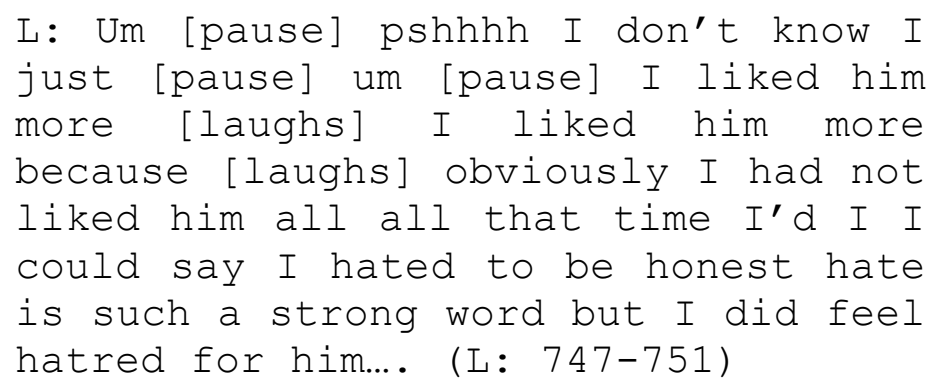

Linda describes the main benefit of mediation for her as becoming a 'better person', demonstrating deep inner transformation. This involved understanding her own mistakes and tendencies, and becoming able to establish a more mature and positive relationship with others.

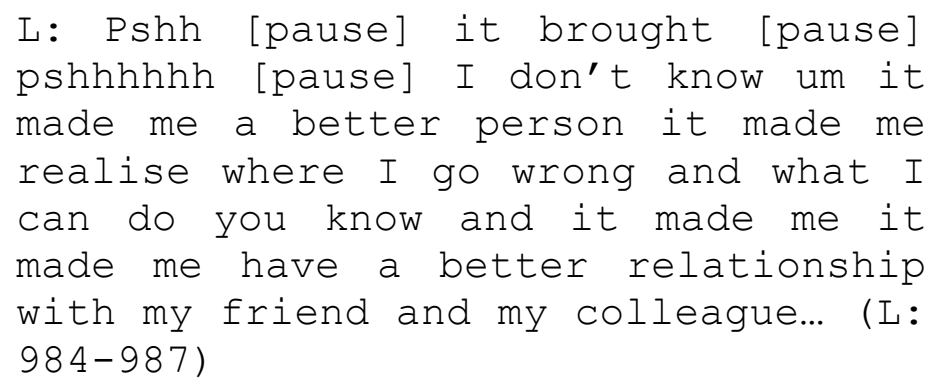

The difficulty of articulating the lessons learned in mediation underlines that this information is not readily accessible for participants and may require dialogical context and stimulation to surface. This adds support to the finding that mediation is capable of eliciting learning, being a facilitated dialogue inducing self-reflection (Bohart 2007).

\section{Discussion and Recommendations}

There is a shortage of studies in the literature that investigate the lived experiences that individuals engage in when trying to bridge their differences in mediation. This article has sought to address this gap providing an in-depth analysis of two main themes of a qualitative 
This is a prepint of an article accepted for publication in Mediation Theory and Practice Copyright @ 2016 Equinox Publishing Ltd Author: Dr Timea Tallodi, University of Essex School of Law

Email: t.tallodi@essex.ac.uk

study that captures the essence of mediation for participants. The results have provided evidence that learning, encompassing insight and reappraisal, is at the core of participants' experiences of facilitative mediation. This finding has not previously been articulated in the literature, and has permitted an examination of mediation from a new angle. The presented themes portray participants' perceptions of the mediator's tools and approach, involving compassion, and ample expression of understanding and sensitivity toward both parties' needs, which enabled learning, facilitating resolution. The findings demonstrated that the lessons learned, irrespective of reconciliation, had enabled all participants to deal with their work situation and relationships more successfully. For most participants learning induced behavioural and emotional changes beyond the scope of mediation, which incorporated elements of personal development.

There are some key ideas that this research highlighted. First, the results suggest that knowledge of learning as the core of mediation needs to be embraced by practitioners and researchers. Mediators should place facilitation of insight and reappraisal in the forefront of their intervention, requiring a clear understanding of these processes and structuring mediation to centre on these. Active listening and rewording, key tools in mediation (Beer and Packard 2012), could be used with the explicit aim of promoting insight and reappraisal.

Second, while the literature lists safe space, encouragement, and highlighting positive content, as integral part of the mediator's intervention (Doherty and Guyler 2008), this study linked these tools to the learning process. The analysis highlighted the importance of parties' perceptions of the mediator's authentic interest in their concerns as pervading the use of these tools. Therefore, while mediators' practices may be guided by their personal affinities (Kressel and Gadlin 2009; Shapiro, Drieghe and Brett 1985) the results of this research highlight an approach that promotes learning if the mediator's style allows for its integration. It is recommended that mediators give ample and clear signs of their understanding and sensitivity to both parties' interests and aspirations. This has been identified as laying the foundations of a successful learning process that benefitted reconciliation or developing pragmatic solutions. This finding extends previous claims relating to the necessity of conveying empathy, warmth and building rapport (Herrman, Hollett and Gale 2009), and refines calls for the use of a tone that expresses genuine interest in parties' issues (Beer and Packard 2012). The recommended approach resonates with Bowling and Hoffman's (2000) argument that the mediator, creating an authentic connection with both parties, will influence their ability to negotiate successfully and unlock their own healing potential.

Third, the findings suggest the application of in-person follow-up sessions. While followup is routinely prescribed, its methods and process are frequently not outlined (Beer and Packard 2012; Menkel-Meadow et al. 2005), and research emphasises that follow-up is a commonly neglected part of mediation (McKinney, Kimsey and Fuller 1996; Saundry, Bennett and Wibberley 2013). The analysis of this study indicated that the interviews conducted following IPA's commitment to encourage in-depth engagement with essential and personal content had offered participants a suitable forum to gain heightened awareness of the lessons learned in mediation. Similarly, follow-up sessions with the mediator would provide space and facilitation for elaboration on what took place during and after mediation, helping parties to capitalise on the learning process for the best possible outcomes in mediation.

Fourth, four mediations studied here elicited negative or mixed realisations regarding the participant's work situation. Participants' descriptions have demonstrated that negative insights, though not comfortable, are equally beneficial. Negative recognitions resulted in reappraisal, generating perspective shift, and behavioural change. Therefore, also in these occasions 
This is a prepint of an article accepted for publication in Mediation Theory and Practice Copyright @ 2016 Equinox Publishing Ltd Author: Dr Timea Tallodi, University of Essex School of Law

Email: t.tallodi@essex.ac.uk

mediation has the potential to change parties' focus in life, resulting in more advantageous coping. This underlines that the prevalent measures of mediation fail to capture many of its goals (Hedeen 2004). The category of the success of mediation is recommended to be expanded to include parties' experiences of negative but change-provoking conclusions. These could be explored in interviews, addressing insight and reappraisal, whilst maintaining confidentiality.

While this research has demonstrated the critical importance of learning in mediation and the mediator's caring attentiveness to parties' concerns and aspirations, adding to existing phenomenological insights into mediation (Hoskins and Stoltz 2003; Tallodi 2015), further phenomenological studies on mediation participants' experiences would be beneficial to complement the results. An avenue to extend the current study would be to further investigate learning through cases mediated by different mediators. This approach would potentially offer a more diverse data set, extending the understanding of participants' perceptions of a variety of personal styles and approaches applied by mediators.

It is important to emphasise that parties' openness to change is essential in order for learning to occur in mediation. Thus, this article does not argue that the mediator's intervention following the above recommendations will successfully promote learning in all cases. Rather, knowledge of insight and reappraisal and efficient ways to induce these, in case of parties' readiness for a change, has strong potential for increasing the success of mediation. This will not solely manifest in settlement rates, but may elicit deeper change at the level of the individual and the dyad, affecting their broader environment. 
This is a prepint of an article accepted for publication in Mediation Theory and Practice Copyright ( 2016 Equinox Publishing Ltd Author: Dr Timea Tallodi, University of Essex School of Law

Email: t.tallodi@essex.ac.uk

\section{References}

Alexander, N. (2008) The mediation metamodel: understanding practice. Conflict Resolution Quarterly 26 (1): 97-123. DOI:10.1002/crq.225

Barton, A.B. (2005) Mediation windfalls: value beyond settlement? The perspective of Georgia Magistrate Court Judges. Conflict Resolution Quarterly 22 (4): 419-435. DOI:10.1002/crq.113

Beer, J.E. and Packard, C.C. (2012) The Mediator's Handbook, $4^{\text {th }}$ ed., Gabriola Island, Canada: New Society Publishers.

Beer, J.E. and Stief, E. (1997) The Mediator's Handbook, $3^{\text {rd }}$ ed., Gabriola Island, Canada: New Society Publishers.

Bennett, M.D. and Hughes, S.H. (2005) The Art of Mediation, $2^{\text {nd }}$ ed., Notre Dame, IN.: NITA.

Bohart, A.C. (2007) Insight and the active client. In L.G. Castonguay and C. Hill (eds.) Insight in Psychotherapy 257-274. Washington: American Psychological Association.

Bollen, K. and Euwema, M. (2013) Workplace mediation: an underdeveloped research area. Negotiation Journal 29 (3): 329-353. DOI:10.1111/nejo.12028

Bowling, D. and Hoffman, D. (2000) Bringing peace into the room: the personal qualities of the mediator and their impact on the mediation. Negotiation Journal 16 (1): 5-28. DOI:10.1111/j.1571-9979.2000.tb00199.x

Carey, T.A, Carey, M., Stalker, K., Mullan, R.J., Murray, L.K. and Spratt, M.B. (2007) Psychological change from the inside looking out: a qualitative investigation. Counselling and Psychotherapy Research 7: 178-187. DOI:10.1080/14733140701514613

Colman, M.A. (2009) Oxford Dictionary of Psychology, $3^{\text {rd }}$ ed., Oxford: Oxford University Press.

Crawford, S.H., Dabney, L., Filner, J.M. and Maida, P.R. (2003) From determining capacity to facilitating competencies: a new mediation framework. Conflict Resolution Quarterly 20 (4): 385-401. DOI:10.1002/crq.33

Doherty, N. and Guyler, M. (2008) The Essential Guide to Workplace Mediation and Conflict Resolution: Rebuilding Workplace Relationships. London and Philadelphia: Kogan Page.

Finlay, L. (2014) Engaging in phenomenological analysis. Qualitative Research in Psychology 11 (2): 121-141. DOI:10.1080/14780887.2013.807899

Folkman, S., Lazarus, R.S., Dunkel-Schetter, C., DeLongis, A. and Gruen, R.J. (1986) Dynamics of a stressful encounter: cognitive appraisal, coping, and encounter outcomes. Journal of Personality and Social Psychology 50 (5): 992-1003.

Gabel, S. (2003) Mediation and psychotherapy: two sides of the same coin? Negotiation Journal 19 (4): 315-328. DOI:10.1111/j.1571-9979.2003.tb00791.x

Goldberg, S.B. and Shaw, M.L. (2008) Further investigation into the secrets of successful and unsuccessful mediators. Alternatives to the High Cost of Litigation 26 (8): 149-160.

Greenberg, L.S. (2002) Integrating an emotion-focused approach to treatment into psychotherapy integration. Journal of Psychotherapy Integration 12 (2): 154-189. DOI:10.1037//10530479.12.2.154

Hayes, A.M., Feldman, G.C. and Goldfried, M.R. (2007) The change and growth experiences scale: a measure of insight and emotional processing. In L.G. Castonguay and C. Hill (eds.) Insight in Psychotherapy 231-253. Washington: American Psychological Association. 
This is a prepint of an article accepted for publication in Mediation Theory and Practice Copyright @ 2016 Equinox Publishing Ltd Author: Dr Timea Tallodi, University of Essex School of Law

Email: t.tallodi@essex.ac.uk

Hedeen, T. (2004) The evolution and evaluation of community mediation: limited research suggests unlimited progress. Conflict Resolution Quarterly 22 (1-2): 101-133. DOI:10.1002/crq.94

Hefferon, K. and Gil-Rodriguez, E. (2011) Interpretative phenomenological analysis. Psychologist 24 (10): 756-759.

Herrman, M.S., Hollett, N. and Gale, J. (2009) Mediation from beginning to end: a testable model. In M.S. Herrman (ed.) The Blackwell Handbook of Mediation: Bridging Theory, Research, and Practice 19-82. Hoboken, NJ: Wiley-Blackwell.

Hoskins, M.L. and Stoltz, J.M. (2003) Balancing on words: human change processes in mediation. Conflict Resolution Quarterly 20 (3): 331-349. DOI:10.1002/crq.3900140306

Howitt, D. (2010) Introduction to Qualitative Methods in Psychology. Essex: Pearson Education Limited.

Jones, T.S. (2005) Emotions in mediation: implications, applications, opportunities and challenges. In M.S. Herrman (ed.) The Blackwell Handbook of Mediation: Bridging Theory, Research, and Practice 277-305. Hoboken, NJ: Wiley-Blackwell.

Jones, T.S. and Bodtker, A. (2001) Mediating with heart in mind: addressing emotion in mediation practice. Negotiation Journal 17 (3): 207-244. DOI:10.1111/j.15719979.2001.tb00238.x

Kovach, K.K. (1997) Good faith in mediation-requested, recommended, or required? A new ethic. South Texas Law Review 38: 575-623.

Kovach, K.K. and Love, P.L. (1998) Mapping mediation: the risks of Riskin's grid. Harvard Negotiation Law Review 3 (71): 71-110.

Knight, T.A., Richert, J. and Brownfield, C.R. (2012) Conceiving change: lay accounts of the human change process. Journal of Psychotherapy Integration 22 (3): 229-254. DOI:10.1037/a0028871

Kressel, K. and Gadlin, H. (2009) Mediating among scientists: a mental model of expert practice. Negotiation and Conflict Management Research 2: 308-343. DOI:10.1111/j.17504716.2009.00043.x

Kressel, K., Henderson, T., Reich, W. and Cohen, C. (2012) Multidimensional analysis of conflict mediator style. Conflict Resolution Quarterly 30 (2): 135-171. DOI:10.1002/crq.21061

Lazarus, R.S. (1991) Psychological stress in the workplace. Journal of Social Behaviour and Personality, 6 (7): 1-13.

Lewis, C. (2009) The Definitive Guide to Workplace Mediation and Managing Conflict at Work. Surrey: RoperPenberthy Publishing Ltd Weybridge.

Liebmann, M. (2000) Introduction. In M. Liebmann (ed.) Mediation in Context 9-19. London: Jessica Kingsley.

Love, L.P. (2000a) Training mediators to listen: deconstructing dialogue and constructing understanding, agendas, and agreements. Family and Conciliation Courts Reviews 38 (1): 27-40.

Love, L.P. (2000b) Images of justice. Pepperdine Dispute Resolution Law Journal 29 (1): 29-36.

Mareschal, P.M. (2002) Mastering the art of dispute resolution: best practices from FMCS. International Journal of Public Administration 25 (11): 1351-1377. DOI:10.1081/PAD120013350

McKinney, B.C., Kimsey, W.D. and Fuller, R.M. (1996) A nationwide survey of mediation centers. Mediation Quarterly 14: 155-166. 
This is a prepint of an article accepted for publication in Mediation Theory and Practice Copyright @ 2016 Equinox Publishing Ltd Author: Dr Timea Tallodi, University of Essex School of Law

Email: t.tallodi@essex.ac.uk

Mcintyre, A. and Reynolds, F. (2012) There's no apprenticeship for alzheimer's: the caring relationship when an older person experiencing dementia falls. Ageing and Society 32 (5): 873-896. DOI:10.1017/S0144686X11000699

Menkel-Meadow, C.J., Love, P.L., Schneider, A.K. and Sternlight, J.R. (2005) Dispute Resolution: Beyond The Adversarial Model. New York: Aspen.

Messer, S.B. and McWilliams, N. (2007) Insight in psychodynamic therapy: theory and assessment. In L.G. Castonguay and C. Hill (eds.) Insight in Psychotherapy 9-29. Washington: American Psychological Association.

Pascual-Leone, A. and Greenberg, L.S. (2007) Insight and awareness in experiential therapy. In L.G. Castonguay and C. Hill (eds.) Insight in Psychotherapy 31-56. Washington: American Psychological Association.

Picard, C.A. and Jull, M. (2011) Learning through deepening conversations: a key strategy of insight mediation. Conflict Resolution Quarterly 29 (2): 151-176. DOI:10.1002/crq.20040

Picard, C.A. and Siltanen, J. (2013) Exploring the significance of emotion for mediation practice. Conflict Resolution Quarterly 31 (1): 31-55. DOI:10.1002/crq.21078

Reid, K., Flowers, P. and Larkin, M. (2005) Exploring lived experience. The Psychologist 18 (1): 20-23.

Rhodes, J. and Smith, J.A. (2010) 'The top of my head came off': an interpretative phenomenological analysis of the experience of depression. Counselling Psychology Quarterly 23 (4): 399-409. DOI:10.1080/09515070.2010.530484

Ridley-Duff, R. and Bennett, A. (2011) Towards mediation: developing a theoretical framework to understand alternative dispute resolution. Industrial Relations Journal 42 (2): 106-123. DOI:10.1111/j.1468-2338.2011.00614.x

Riskin, L. L. (1994) Mediator orientations, strategies and techniques. Alternatives to the High Cost of Litigation 12: 111-114.

Rock, E.M. (2004) Mindfulness meditation, the cultivation of awareness, mediator neutrality, and the possibility of justice. Cardozo Journal of Conflict Resolution 6: 347-365.

Rooney, G. (2007) The use of intuition in mediation. Conflict Resolution Quarterly 25 (2): 239253. DOI: $10.1002 / \mathrm{crq} .206$

Saundry, R., Bennett, T., and Wibberley, G. (2013) Workplace mediation: the participant experience. ACAS Research Paper 02/13, London: ACAS.

Saundry, R. and Wibberley, G. (2012) Mediation and early resolution: a case study in conflict management. ACAS Research Paper 12/12, London: ACAS.

Seargeant, J. (2005) The ACAS small firm mediation pilot: research to explore parties' experiences and views on the value of mediation. ACAS Research Paper 04/05, London: ACAS.

Shapiro, D., Drieghe, R. and Brett, J. (1985) Mediator behavior and the outcome of mediation. Journal of Social Issues 41: 101-114. DOI:10.1111/j.1540-4560.1985.tb00857.x

Siegrist, J. (1996) Adverse health effects of high-effort low-reward conditions. Journal of Occupational Health Psychology 1 (1): 27-41.

Smith, J.A. (2011a) Evaluating the contribution of interpretative phenomenological analysis. Health Psychology Review 5 (1): 9-27. DOI:10.1080/17437199.2010.510659

Smith, J.A. (2011b) 'We could be diving for pearls': the value of the gem in experiential qualitative psychology. QMiP Bulletin 12: 6-15. 
This is a prepint of an article accepted for publication in Mediation Theory and Practice Copyright @ 2016 Equinox Publishing Ltd Author: Dr Timea Tallodi, University of Essex School of Law

Email: t.tallodi@essex.ac.uk

Smith, J.A. and Eatough, V. (2006) Interpretative phenomenological analysis. In G.M. Breakwell, S. Hammond, C. Fife-Schaw and J.A. Smith (eds.) Research Methods in Psychology 322-342, $3^{\text {rd }}$ ed., London: Sage.

Smith, J.A. Flowers, P. and Larkin, M. (2009) Interpretative Phenomenological Analysis: Theory, Method and Research. London: Sage.

Smith, J.A. and Osborn, M. (2008) Interpretative phenomenological analysis. In J.A Smith (ed.) Qualitative Psychology: A Practical Guide to Research Methods 53-81, $2^{\text {nd }}$ ed., London: Sage.

Tallodi, T. (2015) Mediation's potential to reduce occupational stress: a new perspective. Conflict Resolution Quarterly 32 (4): 361-388. DOI:10.1002/crq.21121

Thoennes, N.A. and Pearson, J. (1985) Predicting outcomes in divorce mediation: the influence of people and process. Journal of Social Issues 41 (2): 115-126. DOI:10.1111/j.15404560.1985.tb00858.x

Wall, J.A. and Dunne, T.C. (2012) Mediation research: a current review. Negotiation Journal 28 (2): 217-242. DOI:10.1111/j.1571-9979.2012.00336.x

Whelton, W.J. (2004) Emotional processes in psychotherapy: evidence across therapeutic modalities. Clinical Psychology and Psychotherapy 11 (1): 58-71. DOI:10.1002/cpp.392

Wimpenny, P. and Gass, J. (2000) Interviewing in phenomenology and grounded theory: is there a difference? Journal of Advanced Nursing 31 (6):1485-1492.

Willig, C. (2008) Introducing Qualitative Research in Psychology, $2^{\text {nd }}$ ed., Berkshire: McGrawHill Open University Press. 